\title{
Influence of zinc molybdenum phosphate pigment on coatings performance studied by electrochemical methods
}

\author{
J. Molina², M. Puig', M.J. Gimeno ${ }^{1}$, R. Izquierdo², J.J. Gracenea ${ }^{1,2}$, J.J. Suay ${ }^{1,2}$ \\ ${ }^{1}$ Mediciones y Corrosión S. L. Avda. Vicente Sos Baynat s/n 12006 Castellón, Spain \\ 2 PIMA Research Group, Universitat Jaume I, Avda. Vicent Sos Baynat s/n, 12071 Castellón, Spain. \\ Correspondences should be addressed to J.Molina, javymolina22@gmail.com \\ Abstract
}

The effect of the addition of the zinc molybdenum phosphate pigment, on the corrosion resistance properties of powder coating on steel, has been investigated by means of different electrochemical methods: electrochemical impedance spectroscopy (EIS) and the accelerated cyclic electrochemical technique (ACET). Anticorrosive properties obtained from both techniques showed similar results. Powder coatings incorporating this pigment have shown better performance which is attributed to both barrier properties enhancement and inhibition action of the pigment. This behavior can be correlated to the results obtained in the pigment extract study (polarization test and EIS). Finally, salt fog spray test was performed to confirm the electrochemical tests results.

\section{Introduction}

Using coatings and paints is the most widely used method to protect metals from corrosion. The protection mechanism of each coating is determined by several factors but can be summarized in three effects that act combined: physical barrier (hindering diffusion pathways of water and oxygen to the substrate), chemical inhibition and electric resistance [1-2].

Pigments are one of the principal components of a coating formulation and part of their function is to strengthen the physical and chemical properties of the coating acting as corrosion inhibitors [3]. Zinc molybdenum phosphate seems to have become into an excellent alternative to toxic inhibiting pigments due to its similar anticorrosive behaviour to chromates and better than non-modified zinc phosphates. This pigment belongs to the second generation of zinc phosphates that are obtained by applying an organic surface treatment to the particles, designed to enhance the continuity between the inorganic pigment and the surrounding organic binder $[4,5]$.

Zinc molybdenum phosphate pigment produces a molybdate anion $\left(\mathrm{MoO}_{4}{ }^{-2}\right)$ that acts as an effective anodic inhibitor $[6,7]$ whose capacity to passivate is only slightly lower than the one of the chromate anion [8]. Among all the molybdate-based pigments, zinc molybdenum phosphate is one of the highest reported due to a synergistic effect between the phosphate and the molybdate ions $[9,10]$. According to the literature [11], this dual metal pigment provides higher degree of passivation than zinc chromate 
under acidic conditions but inferior under alkaline conditions. Although there have been several studies to investigate the anti-corrosion efficiency of pigments, most of them are comparative studies of extracts for different types of pigments [12-14] or comparative studies for coatings formulated with such inhibitors [15]. Only few studies are focused on a complete electrochemical investigation to establish the mechanism of action of a specific pigment [16].

In despite the fact that the application of electrochemical impedance spectroscopy (EIS) to coated metals has been shown to be a useful technique in the study of the performance of pigments and coatings [17-23], there is still a great interest in creating rapid assessment methods for practical applications in order to provide faster indications of corrosion processes in the surface and the interface of coated metallic substrates. Hollaender et al. [24-26] developed a rapid method for testing coated metals in food packaging which consists on a combination of cathodic polarization (DC) and EIS measurements (AC). The accelerated cyclic electrochemical technique (ACET) [27-32] is based on the Hollaender method but uses a new potential relaxation step following each cathodic polarization, which is used to evaluate the adhesion of the coating to the substrate. This technique has been used in previous works to study the effect of corrosion inhibitors and other additives that promotes adherence in epoxy, alkyd and polyester powder coatings.

The aim of this paper is to investigate the inhibition mechanism of zinc molybdenum phosphate using electrochemical tests for both bare steel samples in the pigment extracts in $3.5 \mathrm{wt}$. \% $\mathrm{NaCl}$ solution and for pigmented polyester powder coatings.

\section{Experimental}

\subsection{Anticorrosive pigment}

Pigment was obtained from Nubiola ${ }^{\circledR}$ (Nubirox 106) and it is based on a mixture of zinc phosphate and zinc molybdate conditioned with an organic titanate in the surface. The chemical composition of the pigment is described in Table 1.

Table 1. Composition for Nubirox 106

\begin{tabular}{cc}
\hline Compound & $\%$ (weight) \\
\hline \% Trizinc bis(ortophosphate) & $87-97$ \\
Zinc Oxide & $1-10$ \\
Organic titanate & $1-5$ \\
\hline Molybdenum and zinc tetraoxide & $0.5-5$ \\
\hline
\end{tabular}




\subsection{Pigment extract preparation}

$5 \mathrm{~g}$ of zinc molybdenum phosphate pigment in $250 \mathrm{~g}$ of distilled water were used. The solution was stirred for 24 hour at $800 \mathrm{rpm}$ and then filtered to obtain the pigment extract. The solubility of the pigment was $32 \mathrm{mg} / 100 \mathrm{~mL}$, determined from the measurement of the weight of the dried residue of the pigment extract. Finally, $3.5 \mathrm{wt}$. \% NaCl was added to the total pigment extract and then used as a test solution.

\subsection{Powder coating formulations / Sample preparation}

The coatings were developed from a saturated carboxylate polyester resin of low molecular weight (Reafree 8585 from Cray Valley Iberica, S.A.) to combine with a hydroxyalkylamide crosslinker (Primid-XL 552 from EMS-GRILTECH). Other inorganic fillers and additives used were titanium dioxide (Kronos 1171), barite (R-2 from Miber Minerales Roset), a flow agent (Additol from Cytec-Liquid Coatings Resins \& Additives), a levelling agent (Cray-Vallac-PC from Cray-Valley Ibérica), a degassing agent (benzoin from DSM Special Products), a surface hardener (Licowax PE520) and a Teflon wax (Ceridust 9610F from Clariant).

The components of coatings $A$ and $B$ (Table 2) were pre-mixed and shaken by hand until a good premixing was obtained. Subsequently, the mixture was extruded in a double screw extruder (Werner \& Pfleiderer ZSK25) and the temperature profile was set at 40,120, 120 and $70{ }^{\circ} \mathrm{C}$ (rear to front along the extruder). The material produced was ground in an ultracentrifugal mill ZM 100 and sieved at $140 \mathrm{~nm}$; thus, obtaining the different powder coatings ready for study. Coating $A$ is used as a control sample and Coating $B$ replaces barium sulphate with the anticorrosive pigment.

Table 2. Coatings formulation

\begin{tabular}{ccc}
\hline Material & A & B \\
\hline Resin & 46,2 & 46,2 \\
\hline Crosslinker & 2,6 & 2,6 \\
\hline TiO $_{2}$ & 30 & 30 \\
\hline Barium sulphate & 16,9 & 1,9 \\
\hline Degassing agent & 3,0 & 3,0 \\
\hline Levelling agent & 0,5 & 0,5 \\
\hline Benzoin & 0,3 & 0,3 \\
\hline Polyamide wax & 0,3 & 0,3 \\
\hline TFPE wax & 0,2 & 0,2 \\
\hline Zinc molybdenum phosphate & - & 15,0 \\
\hline PVC & 19 & 20 \\
\hline
\end{tabular}




\begin{tabular}{ccc}
\hline PVC/CPVC & 50 & 47 \\
$\lambda$ & 0,38 & 0,43 \\
\hline
\end{tabular}

The carbon steel panels (100 mm x $150 \mathrm{~mm} \times 1 \mathrm{~mm}$ ) were provided by Espancolor S.L having an average surface roughness below 0.50 microns according to the supplier. The formulations were deposited on the metallic substrates, previously degreased with acetone, by means of an electrostatic gun. All the coated samples were cured at $180^{\circ} \mathrm{C}$ for $15 \mathrm{~min}$ and the thicknesses obtained were $90 \pm 10 \mu \mathrm{m}$.

2.4 Testing methods and equipment

\subsubsection{Linear polarization}

Potentiostatic polarization measurements were performed on an Autolab PGSTAT30 potentiostat with a three electrode system. The electrochemical cell was obtained by sticking a glass cylinder on the sample sheet and filling it with the test solution. The exposed surface area was $9.62 \mathrm{~cm}^{2}$. A three-electrode system was used, in which the sample without coating acts as working electrode, a carbon sheet acted as counter electrode and an $\mathrm{Ag} / \mathrm{AgCl}$ electrode was used as reference electrode. This is the most common electrochemical cell setup used in electrochemistry, although other electrode systems are developed to minimize perturbation of signals at high frequency domain when using $\mathrm{Ag} / \mathrm{AgCl}$ electrode [33].

In this technique, an external potential is applied to the working and counter electrodes by the potentiostat to polarize the metal. Then, the release of metal ions occurs toward the counter electrode where the cathodic reaction takes place. The voltammogram obtained determines the current density and corrosion potential which is directly related to the corrosion rate.

Linear polarization tests were carried out on the pigment extract using a potentiodynamic scan of -300 / $+300 \mathrm{mV}$ around the open circuit potential at a scan rate of $1 \mathrm{mV} / \mathrm{s}$. Tafel analysis of the polarization curves are performed using NOVA software, developed by Autolab.

\subsubsection{EIS}

EIS tests were carried out on the coated samples exposed to $3.5 \mathrm{wt}$. $\% \mathrm{NaCl}$ in deionized water. This technique was also performed on an Autolab PGSTAT30 potentiostat employing the same cell described above. The impedance tests were carried out inside a Faraday cage over a frequency range from $100 \mathrm{kHz}$ to $10 \mathrm{mHz}$ using a sinusoidal voltage of $10 \mathrm{mV}$ amplitude in order to minimize external interferences on the system. 
The experimental electrochemical data were collected, analyzed by using NOVA software, and modeled with the equivalent circuits described in Fig. 1, depending on the electrochemical behavior. The circuit 1a consists of an electrolyte resistance Rs, coating pore resistance $R_{p o}$, coating capacitance Cc, polarization resistance $R_{p}$ and double layer capacitance $C_{d l}$. On the other hand, $1 b$ incorporates an oxide layer resistance $\mathrm{R}_{\mathrm{ox}}$ and capacitance $\mathrm{C}_{\mathrm{ox}}$. Fitting the EIS data to the corresponding equivalent circuit by means of Z-view software determined the values of its passive elements, which are generally assumed to be related to the corrosion properties of the system [34]. $R_{p o}$ can be related to porosity and the deterioration of the coating, $C_{c}$ to the water absorption by the coating, $R_{p}$ to the polarization resistance of the interface between the coating and the metal substrate, and $C_{d l}$ to the disbonding of the coating and onset of corrosion at the interface [35-37]. Finally, Cox and Rox describe the evolution of corrosion products at the interface.

To obtain more precise fitting results, constant phase elements (CPE) replaced capacitive elements in the equivalent circuit, providing the software values of $Y_{0}$ in units of $s^{n} / \Omega$ together with a parameter known as " $n$ " instead of $s / \Omega$ units. Mansfeld et al. [34] reported that CPE parameter $Y_{0}$ could be converted into a capacitance $\mathrm{C}$ by using the following equation:

$$
C=Y_{0}\left(w_{\text {max }}^{\prime \prime}\right)^{n-1}
$$

where $w^{\prime \prime}{ }_{\max }$ is the angular frequency at which the imaginary part of the impedance ( $\left.Z^{\prime \prime}\right)$ has a maximum in the Nyquist plot representations. In this study, the effective $C_{d l}$ was calculated using the above equation because $\mathrm{n}$ varies in a wide range. The values used in $\mathrm{C}_{c}$ were those given by the fitting because the $n$ values were always very close to 1 , so no differences were detected. The chi-squared parameter of the fit was always less than 0.01 .
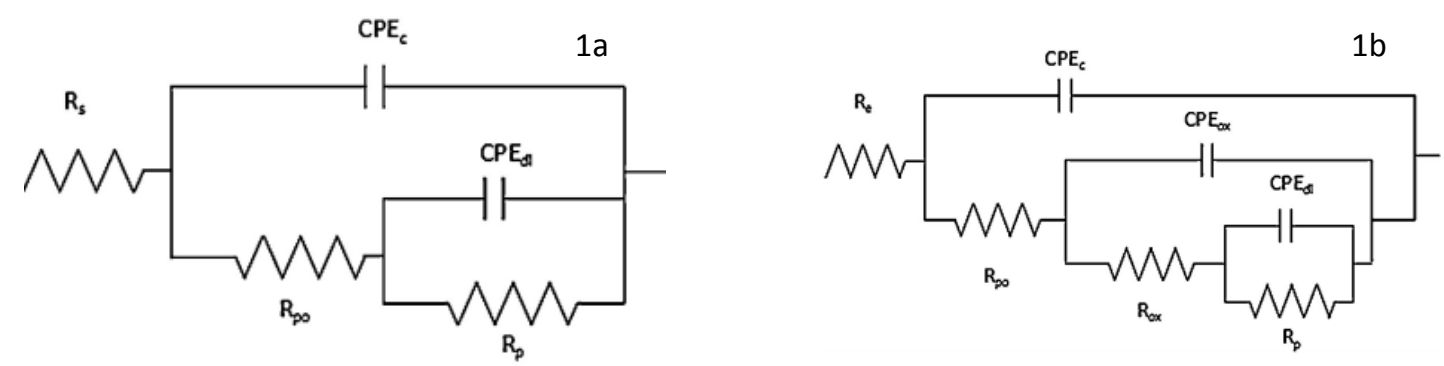

Fig 1. Equivalent circuits used to model EIS and ACET impedance data where passive parameters $\left(R_{s}=\right.$ electrolyte resistance, $\mathrm{R}_{\mathrm{po}}=$ pore resistance, $\mathrm{CPE} \mathrm{E}_{\mathrm{c}}=$ constant phase element of the coating capacitance, $R_{p}=$ polarization resistance, $C P E_{d l}=$ constant phase element of the double layer capacitance, $R_{o x}=$ resistance of corrosion products, $\mathrm{CPE}_{\mathrm{ox}}=$ constant phase element of corrosion layer) can be defined

\subsubsection{ACET}


The ACET procedure comprises a combination of cathodic polarization (DC), potential relaxation and EIS measurements (AC). First, an EIS test is applied to the sample under the conditions described above. This measurement allows the present state of the test sample to be determined. Following the initial EIS measurement, the test sample is treated for a short time with a constant cathodic voltage $(-4 \mathrm{~V})$ for 20 $\min (D C)$ and subsequently, the relaxation time of the sample until it reaches a new steady state and the stabilized potential is registered. In this case, the relaxation time was $3 \mathrm{~h}$. Finally, a new EIS measurement $(A C)$ is applied to the sample in order to evaluate the new state. This test sequence is repeated at least six times, which means that almost 24 hours are required to complete the whole procedure (a schematic representation of the ACET procedure is shown in Fig. 2)

The ACET test is completely automated on the potentiostat. Experimental results obtained by EIS measurements are modeled using the equivalent circuits shown in Fig. 1 and using the same procedure described above.

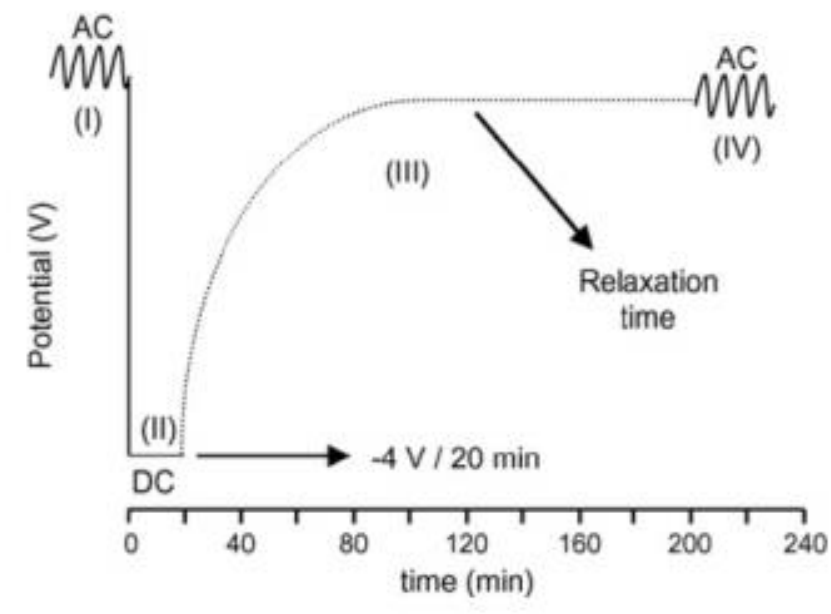

Fig 2. Scheme of the ACET test versus time

\subsubsection{Salt spray fog}

The accelerated salt spray frog test was performed in accordance to the ISO 9227:2012. In this test a scribe is performed along the coating until the bare metal is reached. The samples are then introduced in a salt fog spray chamber where a brine fog is created with $5 \mathrm{wt}$. \% $\mathrm{NaCl}$ water solution. The samples are collected at different periods of time and evaluated until a failure is reached (rusting penetration greater than $2 \mathrm{~mm}$ ).

\subsubsection{Scanning electron microscopy (SEM)}


SEM (JEOL 7001F SEM) was employed to study the morphology of the film formed on the surface of the bare substrate after $24 \mathrm{~h}$ in contact with the pigment extract. The composition of the layers deposition was also evaluated by energy dispersive X-ray analysis (EDX).

\section{Results and discussion}

\subsection{Pigment extract study}

Fig. 3 shows Evans diagrams for control and pigment extracts after 0, 4 and $24 \mathrm{~h}$ in contact with the bare steel substrate. The control sample (Fig. 3a) hardly shows any significant differences between the curves at different contact times.
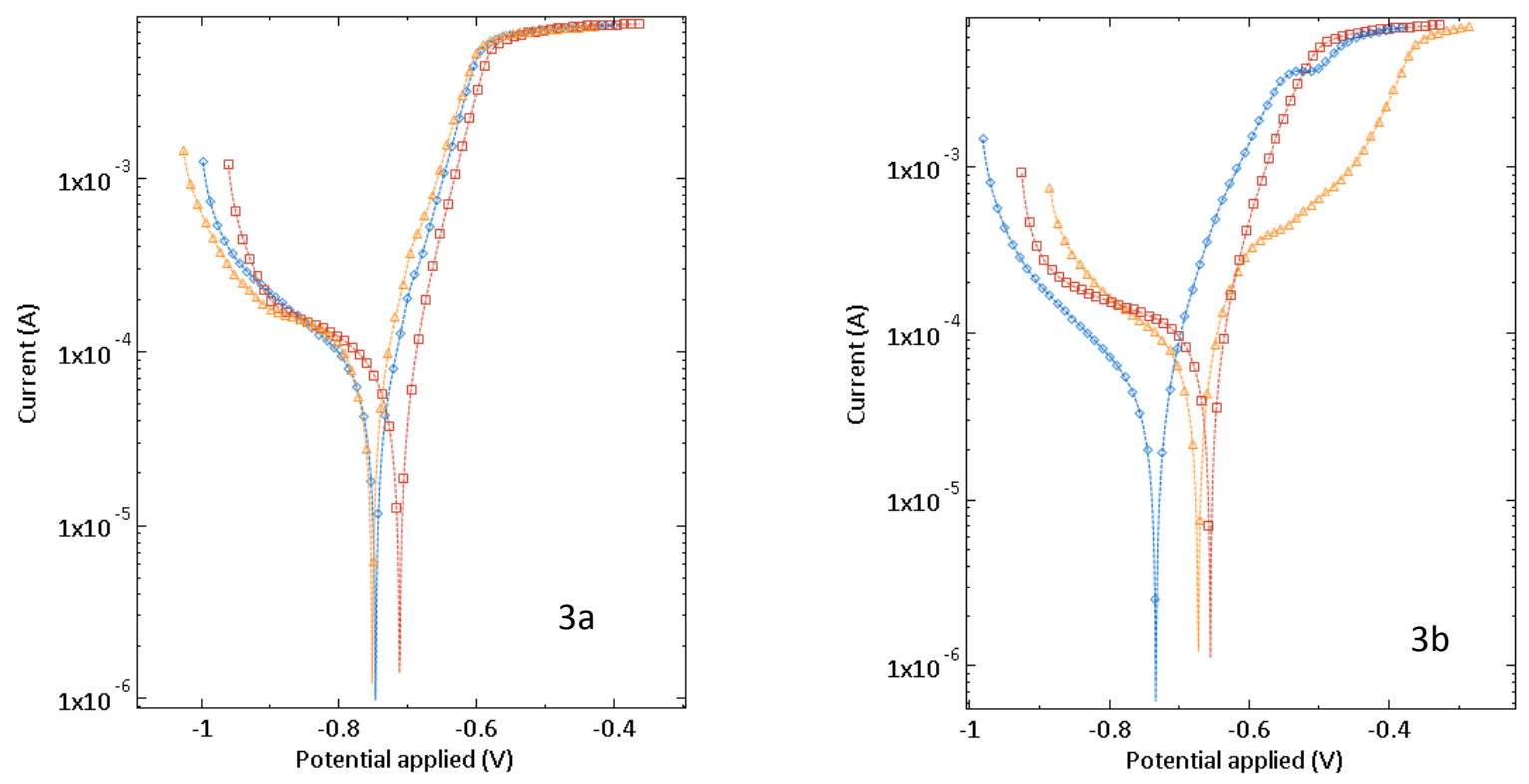

Fig 3. Tafel plots for control (A) and pigment extract $(B)$ at $0 \mathrm{~h}(\square), 4 \mathrm{~h}(\diamond)$ and $24 \mathrm{~h}(\triangle)$

On the other hand, the polarization curves of the pigment extract (Fig. 3b) present more significant differences at different times of exposure. After $4 \mathrm{~h}$ not only a shift can be seen (reflected by the lower corrosion densities), but also a modification on the anodic branch is observed. This is probably due to the active species reaching the interface and partially blocking the process of corrosion. After $24 \mathrm{~h}$ of contact with the pigment extract this behavior is accentuated and the anodic branch of the curve confirms the passivation of the steel. This can be ascribed to the formation of a protective layer derived from the reorganization and reaction of pigment ions at the interface.

Fig. 4a-b shows EIS results for the pigment extract and the control after different times of exposure with the bare steel substrate. In the Bode diagram of the control sample (Fig. 4a) a significant decrease of the impedance modulus with time is observed. In addition, it should be noted that the impedance modulus values are one order of magnitude lower compared to the pigment extract. 
On the other hand, the behaviour of the pigment extract with time is quite different. As can be seen in Fig. $4 \mathrm{~b}$ the impedances values do not significantly change between 0 and $4 \mathrm{~h}$, which can be associated to the process of moving ions and anti-corrosive species to the system interface. After 24 ha slight increase is observed in the impedance that could be due to the reorganization or reaction of these species generating a passivating layer.
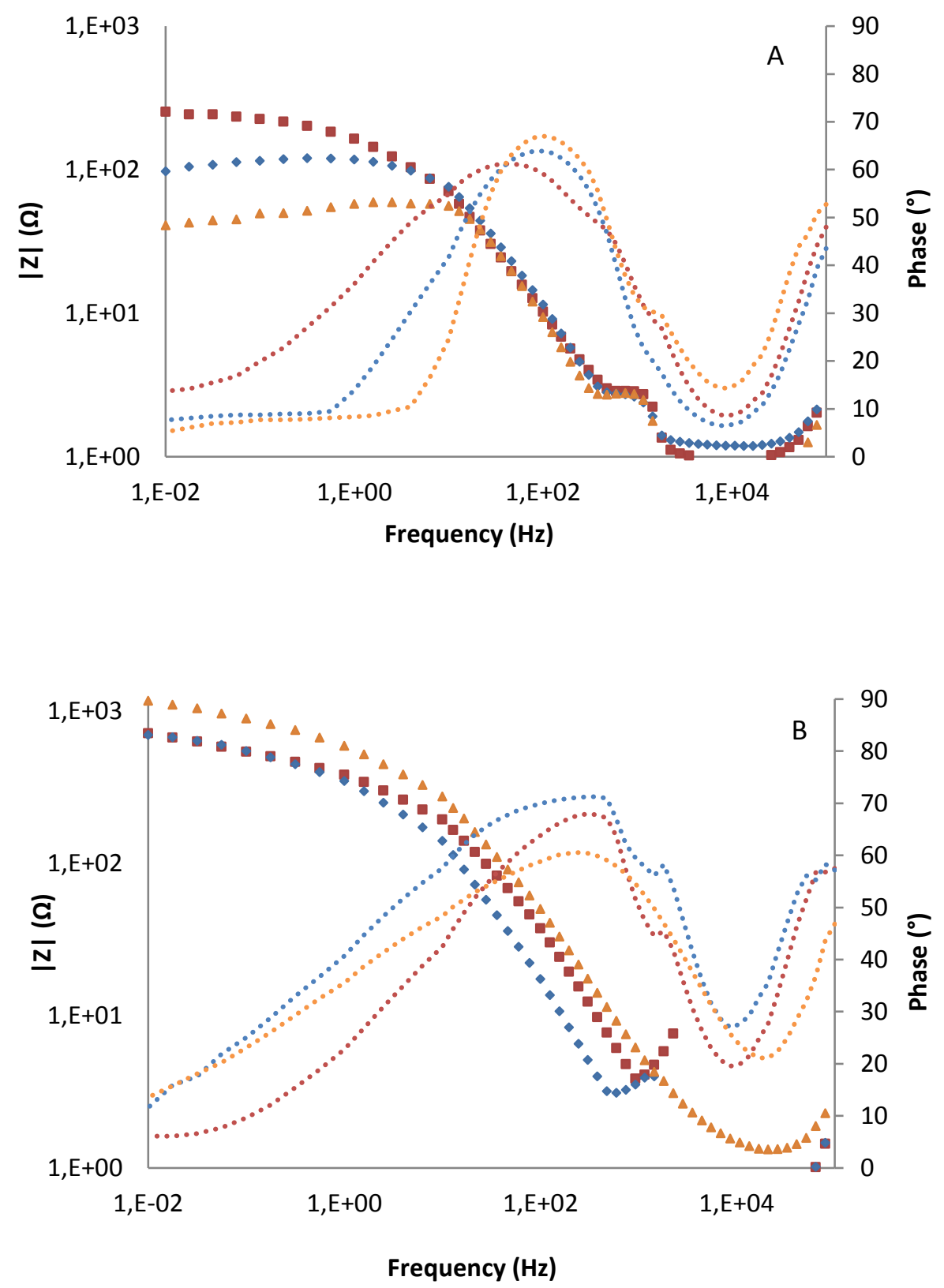

Fig. 4a-b. Bode diagrams of control (a) and pigment extract (b) after $0 \mathrm{~h}(\square), 4 \mathrm{~h}(\diamond)$ and $24 \mathrm{~h}(\triangle)$ in contact with the electrolyte 
In order to analyze and determine the mechanism of action of the corrosion inhibiting pigment, a morphological analysis of the substrate surface after $24 \mathrm{~h}$ in contact with the pigment extract was performed. Fig. 5a shows the micrograph of the surface at 5000x magnification obtained by SEM in backscattered electron mode. The analyzed surface shows a layer of products with different morphology than what is typical observed in iron oxides in corrosion processes [35-36], as can be seen in Fig. 5b where the substrate surface has been in contact with the electrolyte. The EDX analysis of the metallic substrate after the exposure to the pigment extract (Fig.5c)reveals a significant presence of $\mathrm{Zn}, \mathrm{P}$ and Mo, which could indicate the formation of an insoluble passivating complex with different composition than the one formed after the exposure to the electrolyte (Fig. $5 \mathrm{~d}$ ).
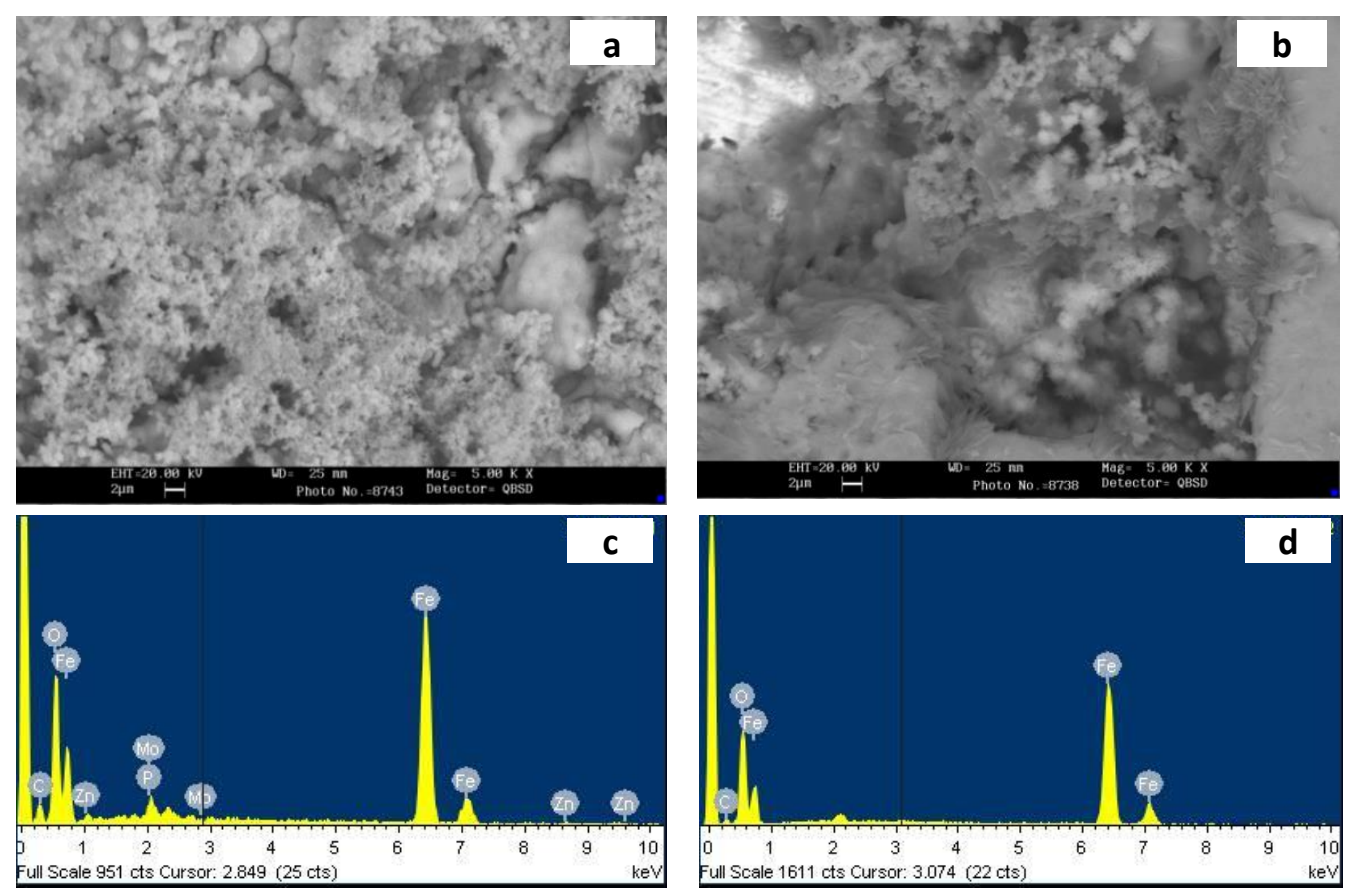

Fig 5. Steel micrograph (5000x) after $24 \mathrm{~h}$ in contact with (a) zinc molybdenum phosphate extract and (b) electrolyte. EDX analysis of the formed films after (c) zinc molybdenum phosphate extract and (d) electrolyte

According to the literature [36-37], a passivating film on the surface of the steel could be formed due to the reaction between the corrosion products of the steel and the inhibiting pigment present in the extract solution by the following mechanisms of action:

Oxidation

$$
\begin{aligned}
& \mathrm{Fe}^{0} \rightarrow \mathrm{Fe}^{+2}+2 \mathrm{e}^{-} \\
& \mathrm{Fe}^{+2} \rightarrow \mathrm{Fe}^{+3}+\mathrm{e}^{-}
\end{aligned}
$$

Reduction

$$
\mathrm{O}_{2}+2 \mathrm{H}_{2} \mathrm{O}+4 \mathrm{e}^{-} \rightarrow 4 \mathrm{OH}^{-}
$$


Precipitation

$$
\begin{aligned}
& \mathrm{Fe}^{+3}+3 \mathrm{OH}^{-} \rightarrow \mathrm{Fe}(\mathrm{OH})_{3} \\
& 2 \mathrm{Fe}(\mathrm{OH})_{3}+\mathrm{Zn}_{3}\left(\mathrm{PO}_{4}\right)_{2} \rightarrow 2 \mathrm{FePO}_{4}+3 \mathrm{Zn}(\mathrm{OH})_{2}
\end{aligned}
$$

Molybdate ions are classified as anodic oxidizing inhibitors. The mechanism by which molybdate inhibits corrosion of steel substrates is typically ascribed to the transformation of the ferrous-molybdate complex (non-protective form) into a ferric-molybdate complex (insoluble and protective in neutral and alkaline water) as a consequence of the presence of dissolved oxygen in water [38].

\subsection{Incorporation of zinc molybdenum phosphate on polyester powder coating}

The zinc molybdenum phosphate pigment was introduced into the coating $\mathrm{B}$ according to the formulation described in Table 1. Coating $A$ is used as a control sample without the incorporation of the anticorrosive pigment.

Fig. 6 shows Bode plot obtained from the EIS test for the coating A applied on steel after different times along $1176 \mathrm{~h}$ of exposure to the electrolyte. It can be observed how the impedance values decrease with time, especially at shorter times. Three time constants on the phase curve can be distinguished after 48 $h$, revealing the formation of corrosion products. This leads to model the spectra with the equivalent circuit of Fig. $1 b$.
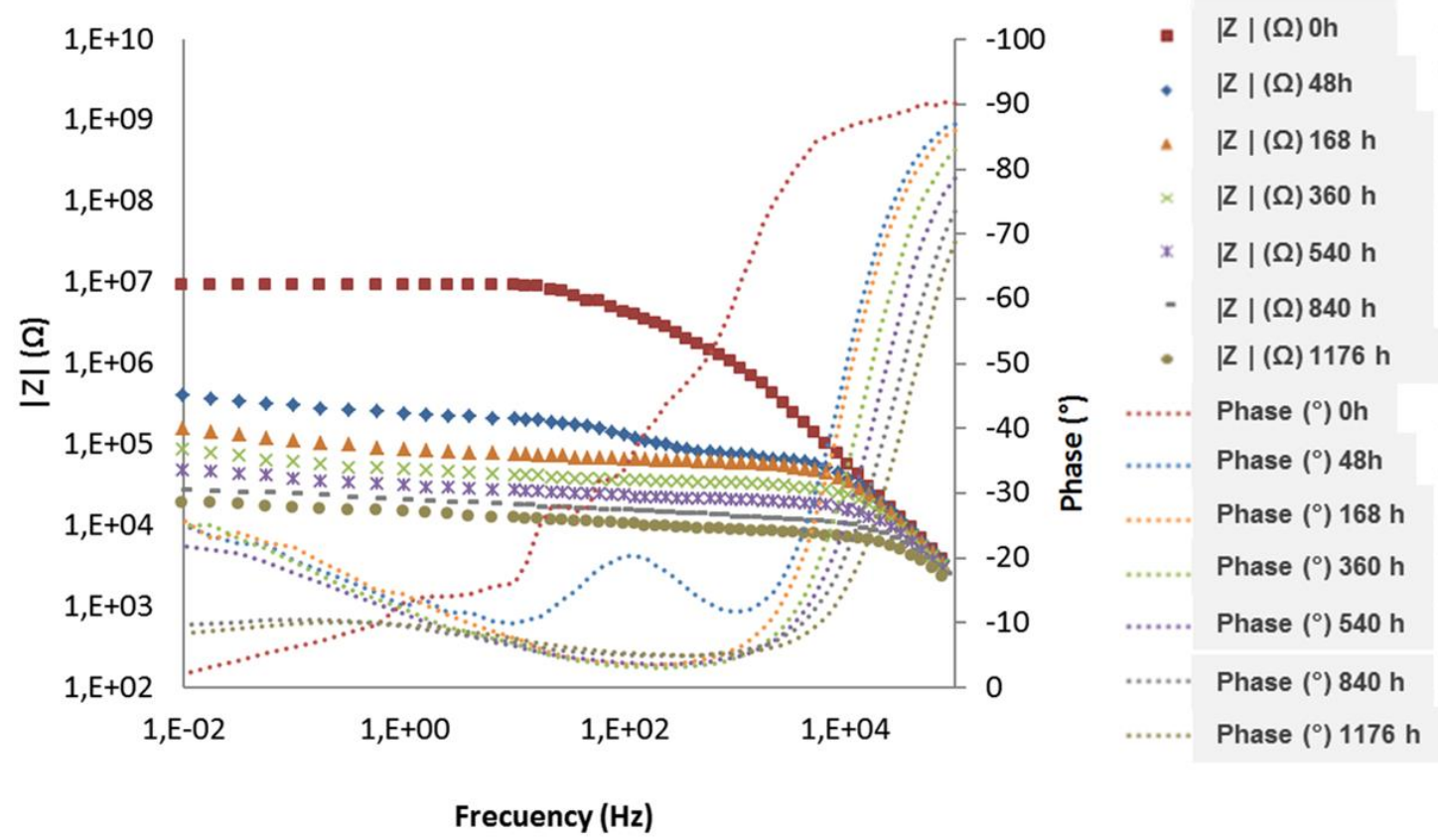

Fig 6. Bode plots of coating A applied on steel after $1176 \mathrm{~h}$ exposure to the electrolyte (deionized water with 3.5 wt. \% NaCl) from EIS tests.

Fig. 7 shows Bode plots obtained from the EIS test for the coating B applied on steel at different times along $1176 \mathrm{~h}$ of exposure to the electrolyte. Higher impedances compared to coating $\mathrm{A}$ at shorter times of exposure can be observed. In this case only two phenomena can be identified (one attributed to the 
coating at high frequencies and the other to the interface at low frequencies) in the phase curve, indicating the presence of two times constants. This means that no corrosion products are formed, confirming the improvement of the coating due to the incorporation of zinc molybdenum phosphate pigment.
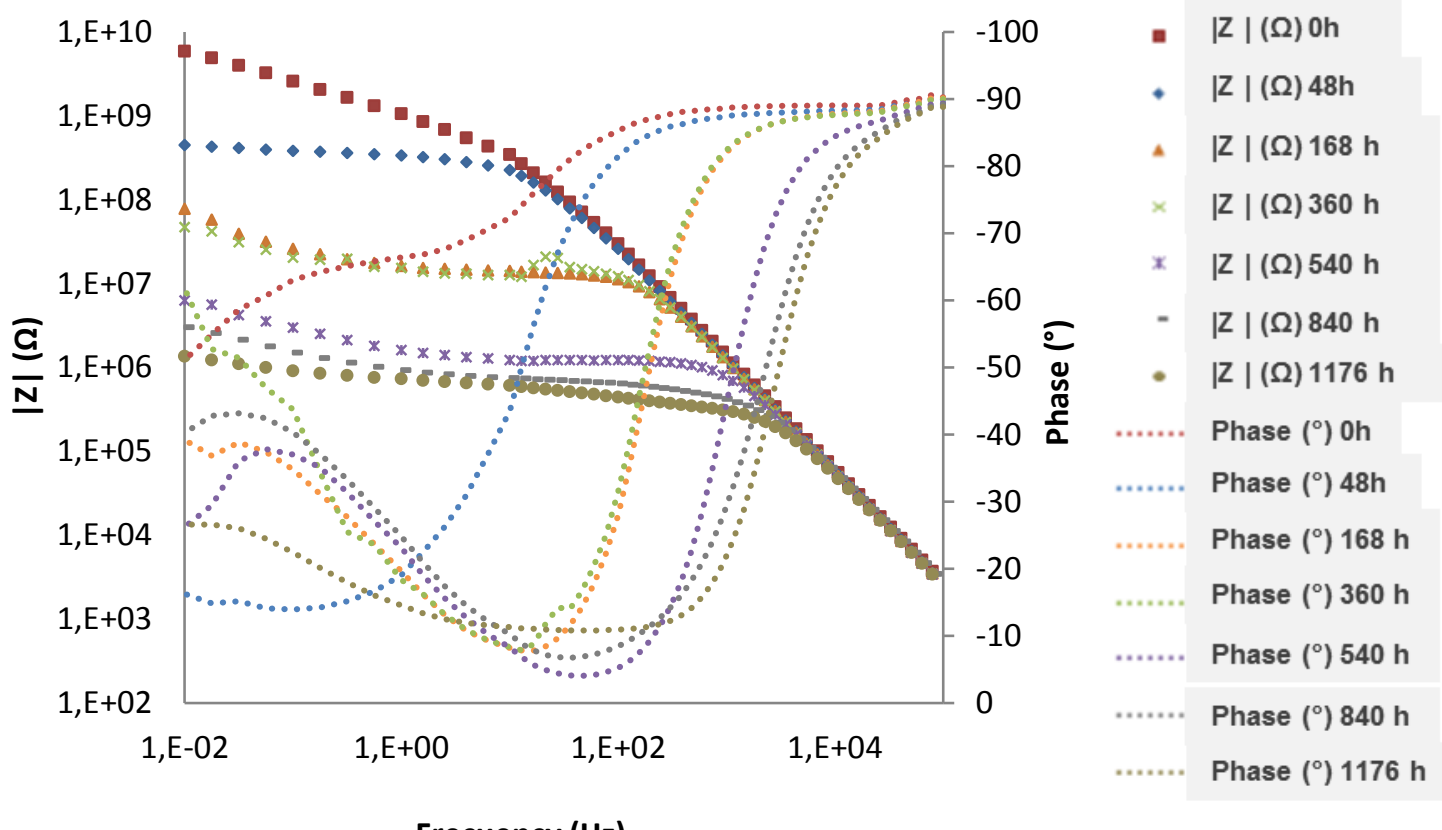

Frecuency $(\mathrm{Hz})$

Fig 7. Bode plots of coating B applied on steel after $1176 \mathrm{~h}$ exposure to the electrolyte (deionized water with 3.5 wt. \% $\mathrm{NaCl}$ ) from EIS tests.

Impedance spectra presented in Fig. 6 and Fig. 7 are modeled according to the equivalent circuits shown in Fig 1 (Coating A with circuit $1 b$ and coating $B$ with circuit 1a). EIS simulation results are presented in Fig. 8.
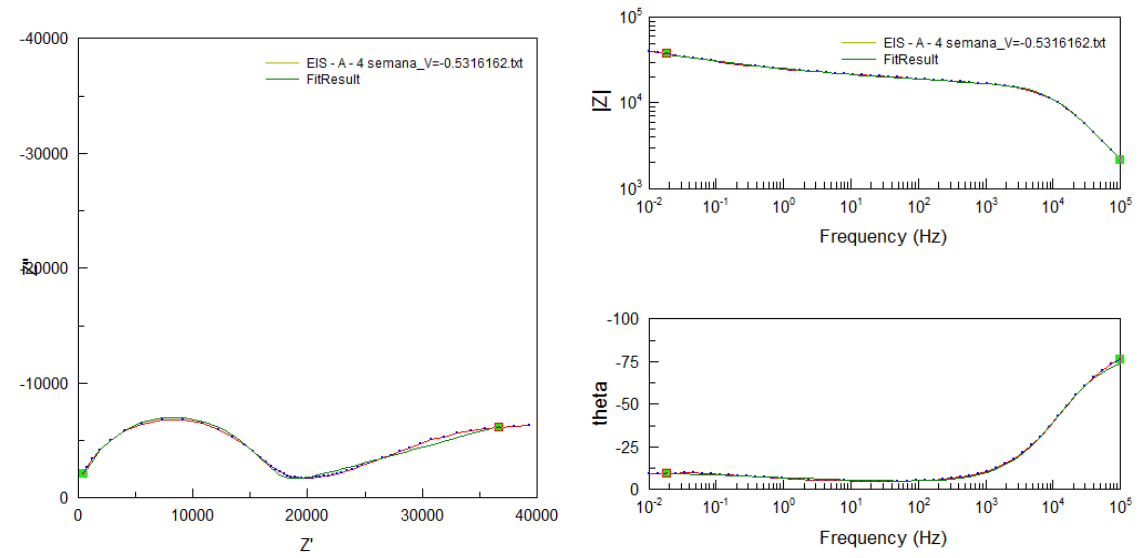


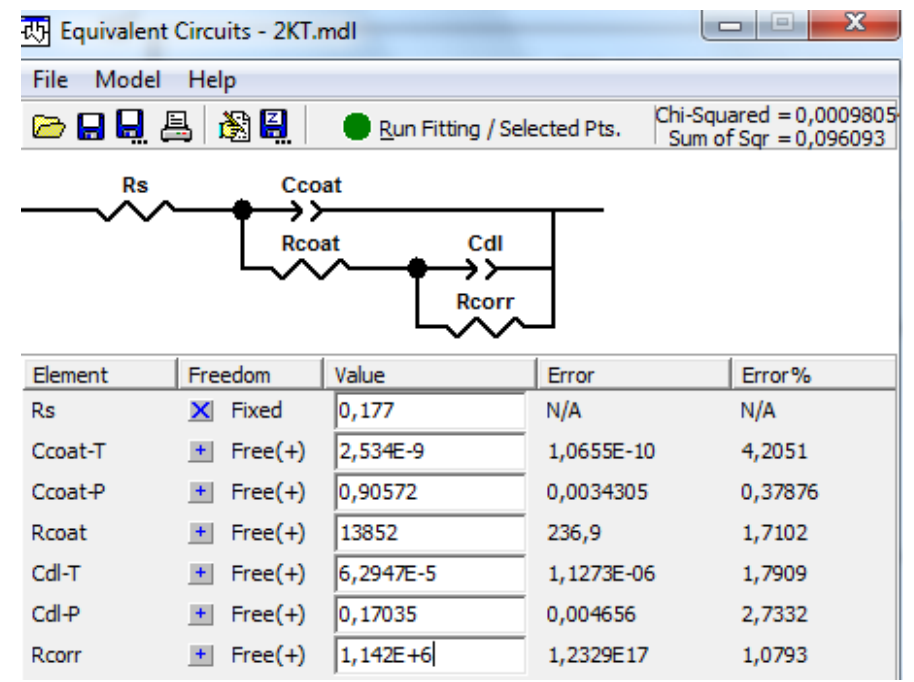

Fig. 8 EIS simulation result for coating A after 4 weeks of exposure with electrolyte

Since coating $A$ and coating $B$ are modeled with different equivalent circuits, a quality differentiation between samples is implicit: anticorrosive behavior of coating B is better than coating A. It can be seen that $R_{p o}$ decreases rapidly at short times and then seems to stabilize after $360 \mathrm{~h}$ for both coating $A$ and coating B (Fig. 9a). However, coating A generally presents lower pore resistance, presumably since it is easier that the electrolyte reaches the interface through the channels forms due to the coating porosity. Anticorrosive pigment addition seems to reduce the permeability of the coating. Coating B presents a stable coating capacitance $\left(C_{c}\right)$ unlike coating $A$ which exhibits a significant increase with time (Fig. 9b). This behavior is attributed to the high absorption of electrolyte within the matrix of the coating $A$. Coating $B$ shows greater values of polarization resistance $\left(R_{p}\right)$ than coating $A$ but both seems to have the same trend at long exposures times (Fig. 9c). This might be due to two different reasons: for coating $A$ the unstable formation of corrosion products and for coating $B$, the passive action of the incorporated pigment. Coating A suggests a more active interface than coating $B$ as can be seen in Fig. $9 d$ due to the formation of corrosion products that lowers the double layer capacitance area. Finally, the graphs of the oxide layer capacitance and resistance ( $\mathrm{C}_{\mathrm{ox}}$ and $\mathrm{Rox}$ ) for coating A (Fig. 9e-f) describe the evolution of corrosion products formed in the interface. The increase of $\mathrm{C}_{\mathrm{ox}}$ with time can be related to a thickness increase of the oxide layer. 

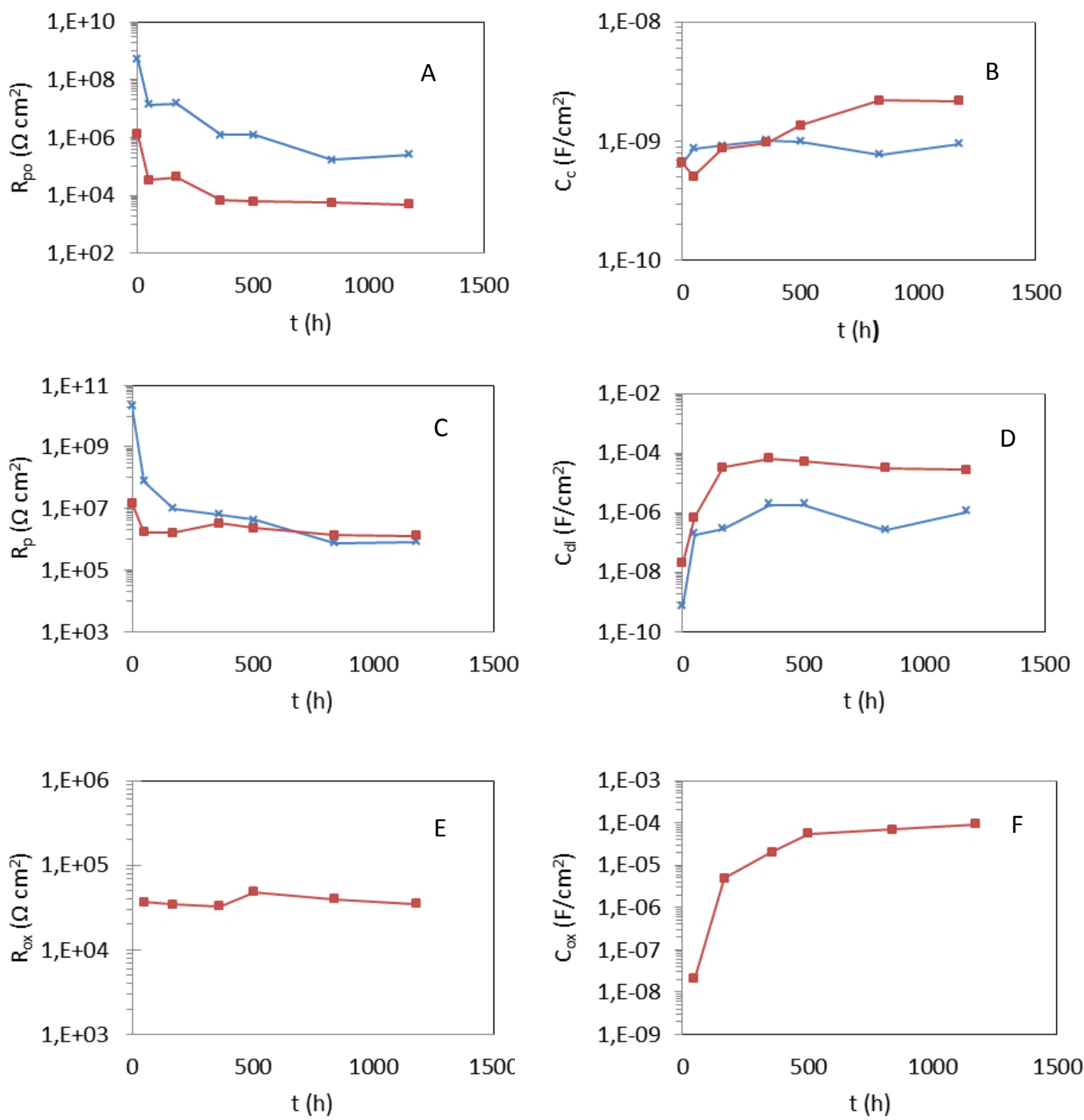

Fig 9. Evolution of: (a) Pore resistance $R_{p o}$, (b) Coating capacitance $C_{c}$, (c) Polarization resistance $R_{p}$, (d)

Double layer capacitance $C_{d l}$, (e) Oxide layer resistance $R_{o x}$ and (f) Oxide layer capacitance $C_{o x}$, for coatings $A(\square)$ and $B(X)$ applied on steel after $1176 \mathrm{~h}$ exposure to the electrolyte (deionized water with 3.5 wt. \% $\mathrm{NaCl}$ ) from EIS tests.

Figs. 10-11 show the impedance results of the ACET test for coatings A and B. Low impedances and the presence of a third time constant after the first cycle can be observed in coating $A$ (from the fourth cycle the plateaus are clearer). These results lead to the need to model the data using a different equivalent circuit from coating B as it occurred in the EIS tests. 


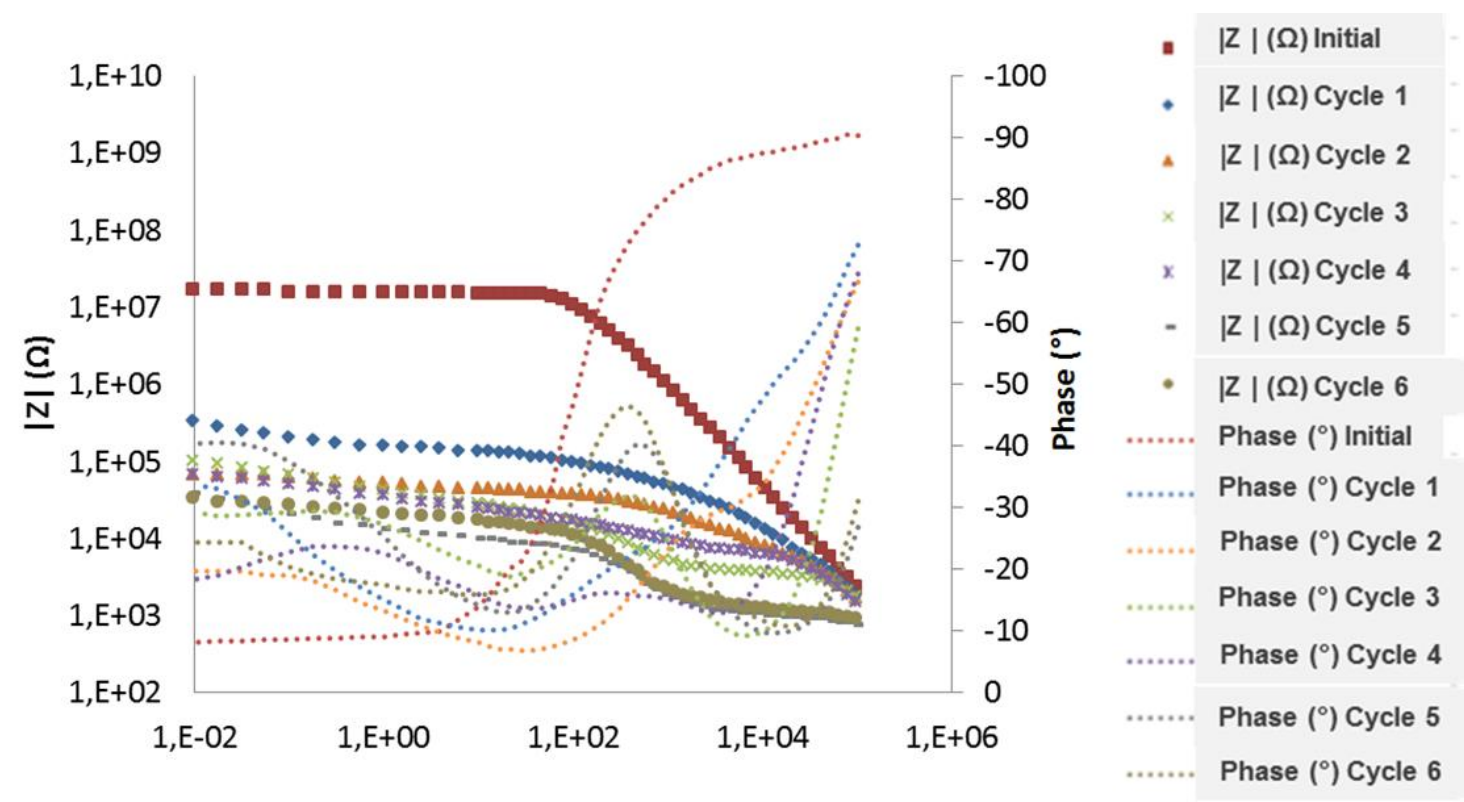

Frecuency $(\mathrm{Hz})$

Fig 10. Bode plots of coating A applied on steel after 6 cycles of cathodic polarizations from ACET test.

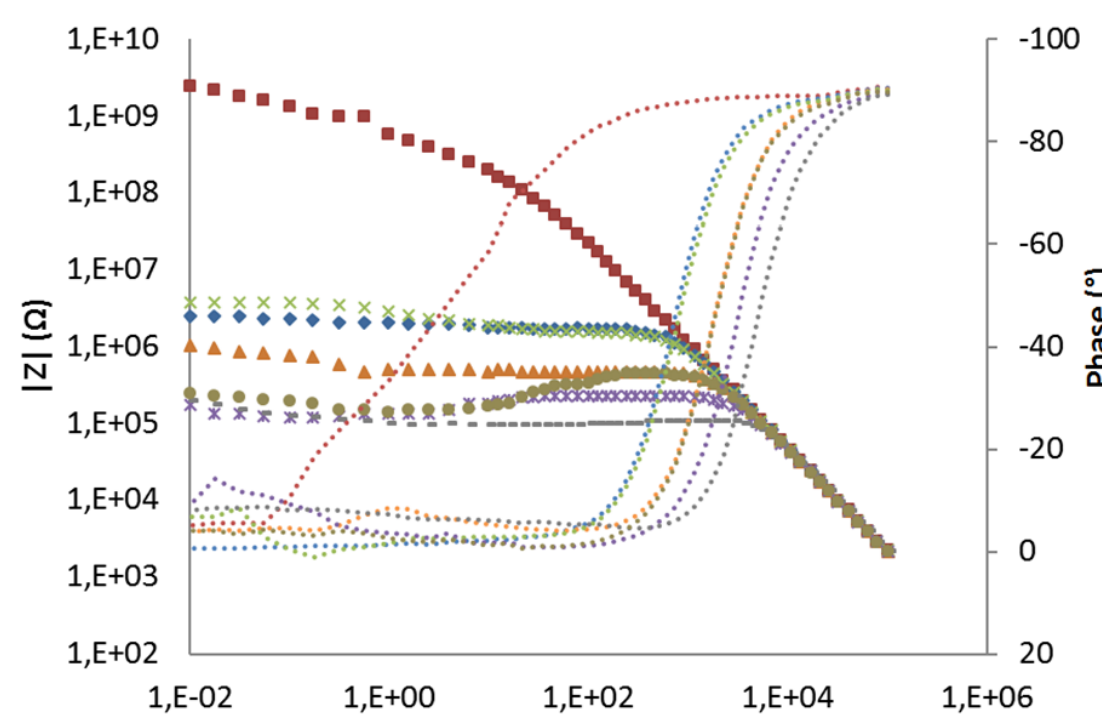

Frecuency (Hz)

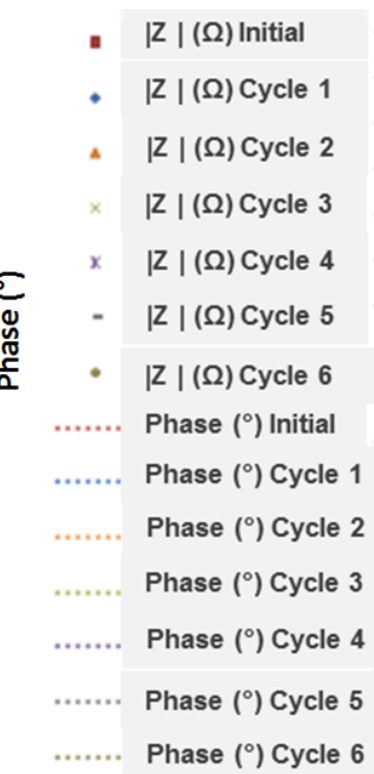

Phase $\left({ }^{\circ}\right)$ Cycle 6

Fig 11. Bode plots of coating B applied on steel after 6 cycles of cathodic polarizations from ACET test.

Fig. 12 shows the evolution of the modeled parameters for the ACET test. It can be seen that Rpo decreases gradually due to the increase of porosity after the polarizations for both coatings $A$ and $B$. Coating A presents lower pore resistance than coating $B$ after all cathodic polarizations, which can be related to the different permeability of the coatings (Coating $A>$ Coating $B$, see Fig. 12a). Coating $B$ presents a stable coating capacitance $\left(C_{c}\right)$ in contrast with coating $A$ that shows unstable values. This behavior is attributed to an initial high absorption of electrolyte, a later saturation of the coating and finally the formation of corrosion products blocking the pores of absorption (Fig. 12b). The polarization 
resistance $\left(R_{p}\right)$ showed in Fig. 12c are quite similar for both coatings as EIS results indicate the formation of corrosion products (coating $A$ ) or a passivating layer (coating B). The $C_{d l}$ evolution (Fig. 12d) suggests a very active interface for coating $A$ with the subsequent formation of corrosion products. On the other hand, $C_{d l}$ for coating B drastically decreases after the fourth cycle attributed to the stabilization of the formed passivating layer. The graphs of the oxide layer capacitance and resistance ( $C_{o x}$ and $R_{o x}$ ) for coating A describe the evolution of corrosion products formed at the interface (Fig. 12e-f). In this case, the produced corrosion products are more unstable than in the EIS test as can be seen in Rox. This might be due to the polarization cycles that induce delamination processes at the interface.
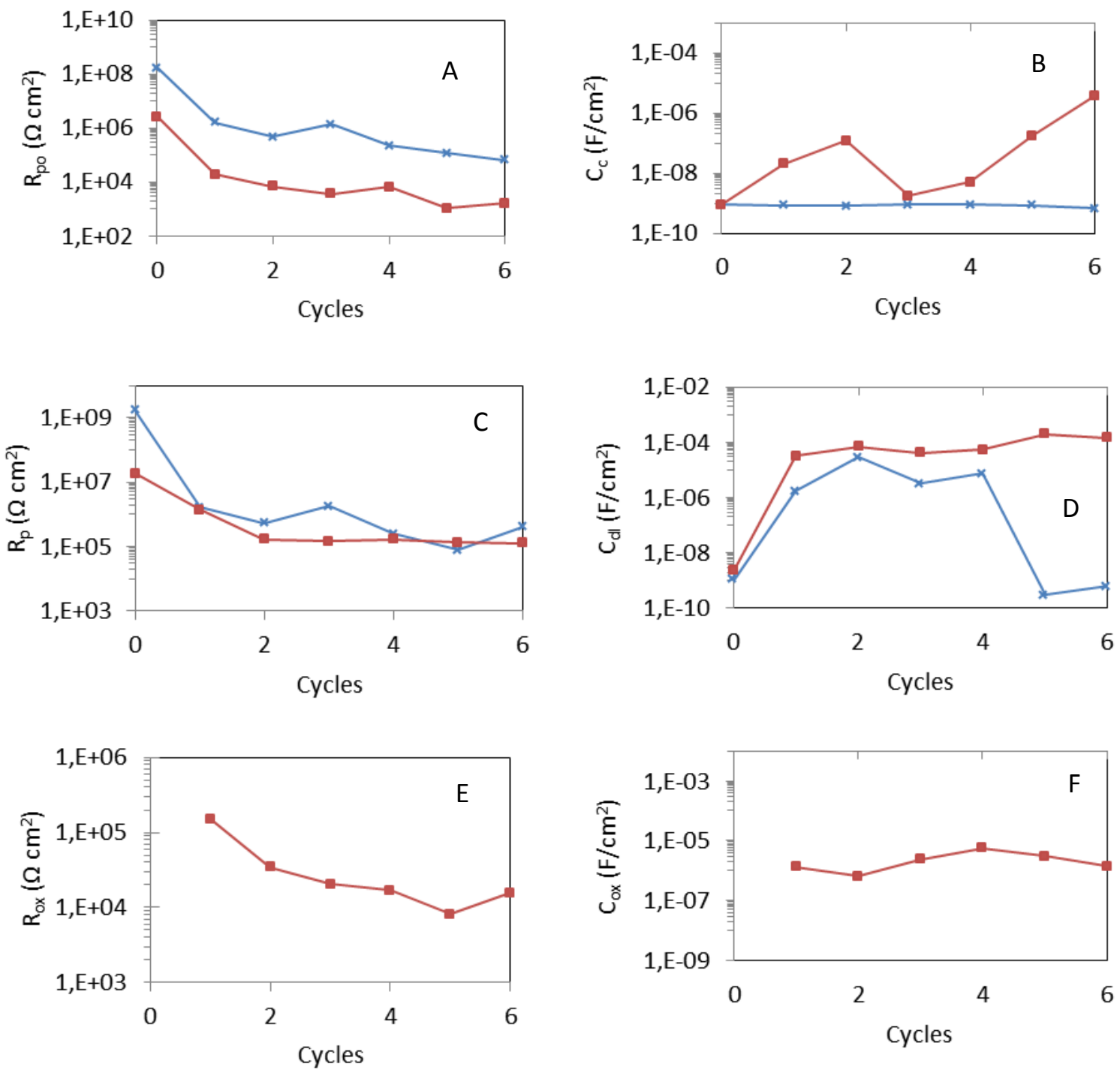

Fig 12. Evolution of: (a) Coating capacitance, (b) Pore resistance, (c) Double layer capacitance, (d) Polarization resistance, (e) Oxide layer capacitance and (f) Oxide layer, for coatings $A(\square)$ and B (X) applied on steel after 6 cycles of cathodic polarizations from ACET test.

Figs. 13 and 14 show the potential relaxation versus time after each cathodic polarization for coating $A$ and B. A significant difference between the relaxation spectra of these coatings can be observed. During 
the polarization step, the penetration of the electrolyte through the coating is forced. This promotes water electrolysis forming $\mathrm{H}_{2}(\mathrm{~g})$, which tends to be released generating delamination processes. This behavior can be observed in relaxation plots when the potential reaches values close to - $1 \mathrm{~V}$. For coating A (Fig. 13), the first relaxation around $-1 \mathrm{~V}$ at short times can be seen, which is related to the stop of hydrogen production due to cathodic polarization. The following relaxations can be related to the formation of double layer and/or the release of hydrogen from the coating. As it can be observed, there is a hydrolysis phenomenon since the first cycle showing high permeability of the coating and low adherence because the electrolyte is able to reach metal interface from the first moment.

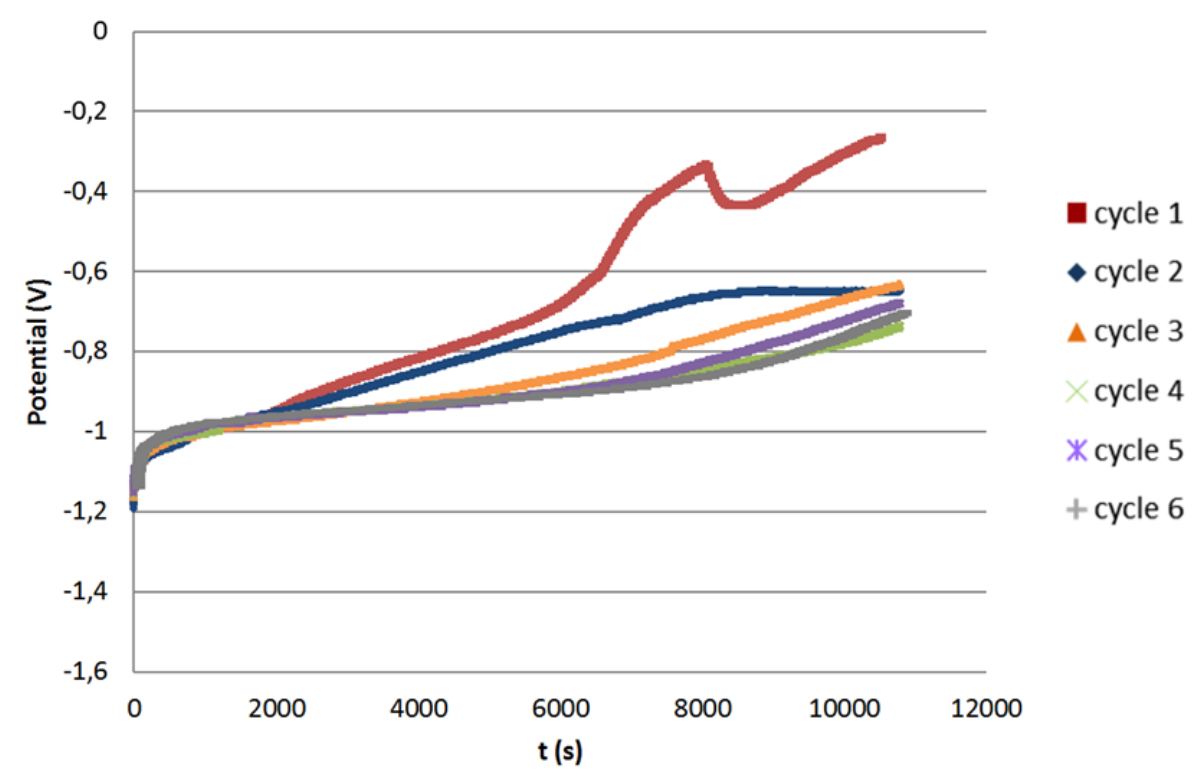

Fig. 13. Evolution of the open circuit potential (EOC) versus the relaxation time after exposure to six cathodic polarizations for coating A from ACET test

On the other hand, coating B presents relaxation curves quite different to coating A (Fig. 12) showing higher potential values. In this case the potential values reached are close to $-0.4 \mathrm{~V}$ in the first three cycles that can be ascribed to the release of ions and electrolyte from the coating. However, as more polarizations are taking place, smaller delamination processes due to hydrolysis are observed, because the potential values decay around $-1 \mathrm{~V}$. Despite this, the interface does not show the formation of an oxide layer unlike coating A (Fig. 10). This action can be attributed to the fact that the zinc molybdenum phosphate incorporated in the coating, reaches the interface preventing the corrosion process. 


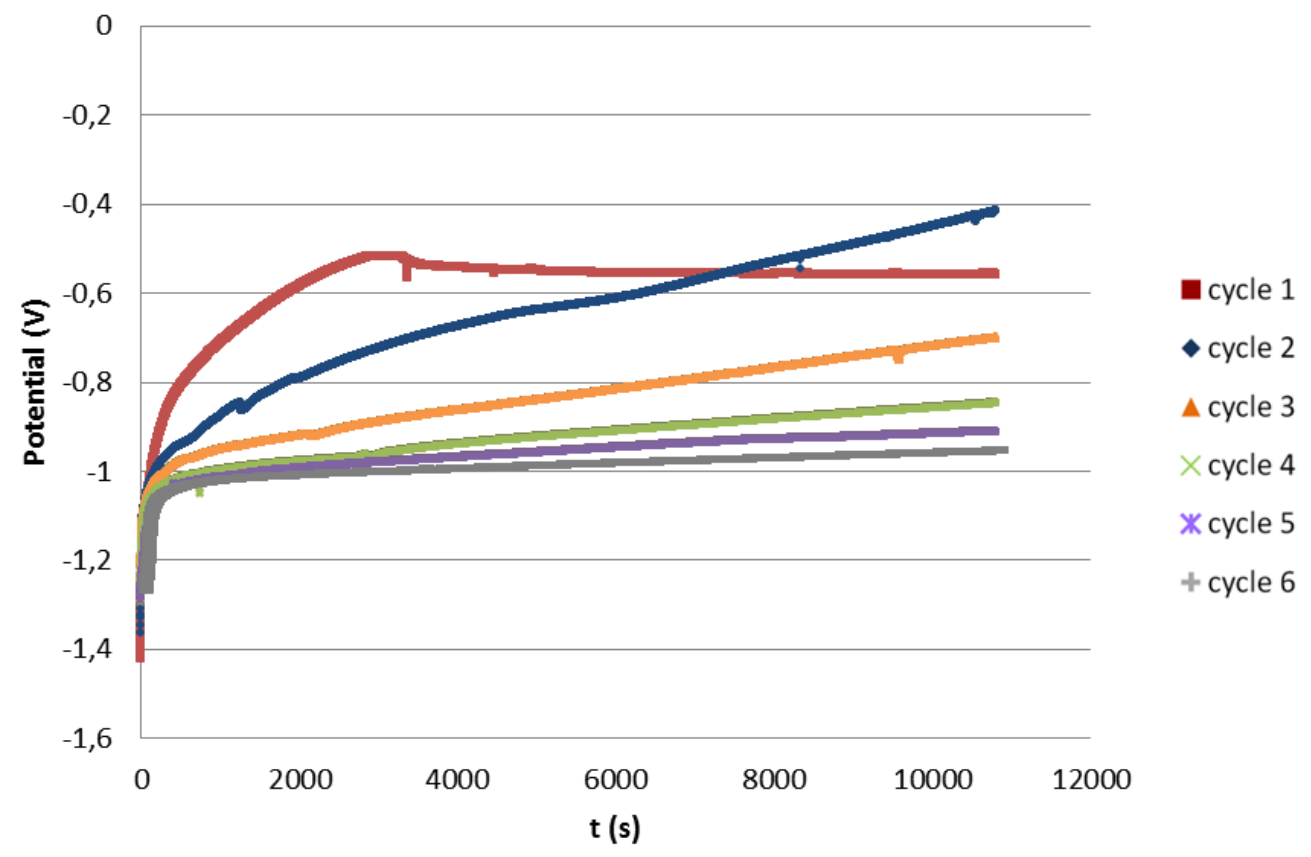

Fig 14. Evolution of the open circuit potential (EOC) versus relaxation time after exposure to six cathodic polarizations for coating B. ACET test

Electrochemcial results have shown that coating B has better anti-corrosive performance than coating A. They have also indicated the possibility of the formation of a passivating layer and this can be correlated with the pigment extract study (section 3.1)
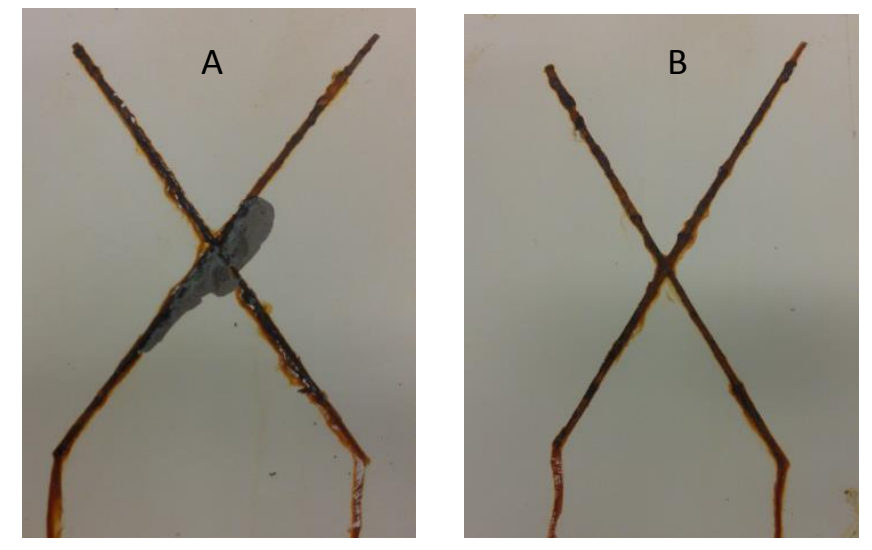

Fig 15. Coating A (A) and B (B) on steel after100 h of salt spray fog

Finally, salt spray fog test was performed. Coating A achieved 100 hon chamber until the failure by delamination occurred. This is compared to the $264 \mathrm{~h}$ achieved by coating B until failure by the same phenomena. This test was carried out following the standard UNE-EN ISO 4628-8 where the samples are evaluated immediately after the exposure time. First, the residues are eliminated and then an adhesive tape is placed and removed at an angle and force set. Using a precision instrument the total width of the area of delamination is measured in a minimum of six points uniformly distributed along the incision. 
Using the mathematical expressions described below, a degree of delamination is obtained. If this value exceeds $1 \mathrm{~mm}$ (according to the ISO 12944), the test is considered as unsatisfactory. The result must be reproduced in at least two of the three samples for deemed representative.

Average value of delamination width $\left(\mathrm{d}_{1}\right)=\frac{M_{1}+M_{2}+M_{3}+M_{4}+M_{5}+M_{6}}{6}$

$$
\text { Delamination grade }(\mathrm{d})=\frac{d_{1}-\text { original incision width }}{2}
$$

Fig. 15 shows the differences between samples after $100 \mathrm{~h}$ of exposure (time at coating A failure). This result confirms the electrochemical tests outcome and concludes the important role of zinc molybdenum phosphate when incorporated in the coating.

\section{Conclusions}

A powder coating formulation incorporating zinc molybdenum phosphate pigment was applied on steel. The anticorrosive properties were studied by means of electrochemical methods (EIS and ACET) and salt spray fog. Results concerning the quality of powder coating formulations obtained with the two electrochemical techniques were quite similar, although the ACET test offered results in significantly shorter times. The different results showed that the anticorrosive properties were enhanced when zinc molybdenum phosphate was added due to the barrier properties improvement and the inhibiting action of the pigment. Salt spray fog confirmed these results obtaining and improvement of $164 \mathrm{~h}$ in chamber. This was correlated with the isolated study of zinc molybdenum phosphate by electrochemical means and showed that the anti-corrosive properties were associated with the process of moving ions and active species to the system interface preventing the corrosion process.

\section{Acknowledgements}

The authors would like to acknowledge Nubiola S.A for supplying the raw materials, as well as Raquel Oliver and José Ortega for their help in the development of this project. 


\section{References}

[1] K. Barton, Protection Against Atmospheric Corrosion, Wiley, New York, 1976, p.106

[2] W. Funke, in R.A. Dickie and F.L. Floyd (eds) Polymeric Materials for Corrosion Control, American Chemical Society, Washington DC, 1986, p. 222.

[3] A. Amairudin, C. Barreau, R. Hellouin, D. Thierry, Prog. Org. Coat. 25 (1995) 339.

[4] M. Beland, Am. Paint Coat. J. 6 (1991) 43.

[5] B. del Amo, R. Romagnoli, V.F. Vetere, J. Appl. Electrochem. 29 (1999) 1401-1407.

[6] A. Forsgren, Corrosion control through organic coatings, CRC Press, Boca Ratón (Florida), 2010.

[7] T. Kodama, J.R. Ambrose, Corrosion. 33 (1977) 155-161.

[8] R. Romagnoli, V.F. Vetere, Corros. Rev. 13 (1995) 45-64.

[9] Z. Yong, J. Zhu, C. Qiu, Y. Liu, Appl.Surf.Sci. 255 (2008) 1672-1680.

[10] C. Dehghanian, M. Saremi, M. Mohammadi Sabet, Iran. J. Mater. Sci. Eng. 2 (2005) 9-15.

[11] M. Bethencourt, F.J. Botana, M. Marcos, R.M. Osuna, J.M. Sánchez-Amaya, Prog. Org. Coat. 46 (2003) 280-287.

[12] R. Naderi, M.M. Attar, M.H. Moayed, Prog. Org. Coat. 50 (2004) 162.

[13] R. Naderi, M.M. Attar, M.H. Moayed, Mater. Corros. 56 (2005) 325.

[14] R. Naderi, M.M. Attar, M.H. Moayed, Electrochimica Acta 53.18 (2008): 5692-696.

[15] J. Havlík, a. Kalendová, D. Veselý, J. Phys. Chem. Solids. 68 (2007) 1101-1105.

[16] Y. Hao, F. Liu, E.H. Han, S. Anjum, G. Xu, Corros. Sci. 69 (2013) 77-86.

[17] F. Mansfeld, J. Appl. Electrochem. 25(3) (1995) 187-202.

[18] G.P. Bierwagen, J. Coat. Technol. 64 (1992) 71-75.

[19] B. Liu, Y. Li, H.C. Lin, C.N. Cao, Acta Phys. Chim. Sin. 17 (2001) 241.

[20] B.S. Skerry, C.T. Chen, C.J. Ray, J. Coat. Technol. 64 (1992) 77-86.

[21] M. Selvaraj, S. Guruviah, Prog. Org. Coat. 28 (1996) 271-277.

[22] L.S. Hernandez, B. del Amo, R. Romagnoli, Anti-Corros. Meth. and Mater. 46 (1999) 198-204.

[23] J. Shao, P. Wan, X. Lin, H. Lin, S. Zhang, Mater. Corros. 46 (1995) 33-38.

[24] J. Hollaender, E. Ludwig, S. Hillebrand, Proc. 5th International Tinplate Conference, London,1992, pp $300 f f$.

[25] J. Hollaender, Food Additives and Contaminants. 14 (1997) 617-626.

[26] J. Hollaender, C.A. Schiller, W. Strunz, Proc. EIS, 2001. 
[27] M.T. Rodriguez, J.J. Gracenea, J.J. Saura, J.J. Suay, Prog. Org. Coat. 50 (2004) 68-74.

[28] J.J. Suay, M.T. Rodriguez, K.A. Razak, J.J. Carpio, J.J. Saura, Prog. Org. Coat. 46 (2003) 121-129.

[29] S.J. García, J. Suay, Prog. Org. Coat. 66 (2009) 306-313.

[30] S.J. García, J. Suay, Prog. Org. Coat. 59 (2007) 251-258.

[31] S.J. García, M.T. Rodríguez, R. Izquierdo, J. Suay, Prog. Org. Coat. 60 (2007) 303-311.

[32] S.J. García, J. Suay, Prog. Org. Coat. 57 (2006) 273-281.

[33] S.W. Watson, B.W. Madsen, Corrosion. 48 (1992) 727-733.

[34] F. Mansfeld, J. Appl. Electrochem. 25(3) (1995) 187-202.

[35] L. Cáceres, T. Vargas, L. Herrera. Corrosion Science 51.5 (2009): 971-78

[36] L. Chuen-Chang, C.X. Wang. Journal of Applied Electrochemistry 35.9 (2005): 837-43.

[37] Romagnoli, R. and V. F. Vetere. Corrosion 51.2 (1995): 116-23.

[38] J. R. Scully, J. Electrochem. Soc.136 (1989) 979. 